\title{
Management of Pseudomonas aeruginosa pneumonia: one size does not fit all
}

\author{
Jordi Rello ${ }^{1,2,3,4^{*}}$, Bárbara Borgatta1,3 and Leonel Lagunes ${ }^{1,3}$ \\ See related research by Lu et al., http://ccforum.com/content/18/1/R17
}

\begin{abstract}
In view of the mortality associated with Pseudomonas aeruginosa (PSA) ventilator-associated pneumonia (VAP) and the frequency of inadequate initial empiric therapy, recent findings underscore the need for a different management paradigm with effective anti-pseudomonal vaccines for prophylaxis of patients at risk. The association of virulence factors is a variable that splits PSA in two phenotypes, with the possibility of adjunctive immunomodulatory therapy for management of virulent strains. We comment on recent advances in and the state of the art of PSA-VAP management and discuss a new paradigm for tailored and optimal management.
\end{abstract}

In the previous issue of Critical Care, Lu and colleagues [1] reported a visionary study assessing the distribution of Pseudomonas aeruginosa (PSA) serotypes in patients with ICU pneumonia and suggested differences in outcomes depending on serotypes. In this report, serotype O6 predominated, being associated with better clinical outcomes than serotype 011 , which were frequently producing toxins secreted by the type III secretion system (TTSS). These findings have important implications for both clinical practice and future studies.

In an international study of over 1,200 ICUs in 75 countries, the risk of infections, including those due to Pseudomonas species, was found to increase with duration of ICU stay; in addition, infection was associated with an increased risk of mortality [2]. In 2014, at a time when multidrug-resistant clones are emerging and represent a strong risk of dissemination, we have much more

\footnotetext{
*Correspondence: jrello@crips.es

'Critical Care Department, Hospital Vall d'Hebron, Passeig de la Vall d'Hebron, 119-129, 08035 Barcelona, Spain

${ }^{2}$ CIBERES, Recinto Hospital Joan March, Carretera Soller Km 1207110,

Mallorca, Bunyola, Illes Balears, Spain

Full list of author information is available at the end of the article
}

information on Pseudomonas pneumonia management. We know that one effective agent is equivalent to two $[3,4]$ but that initial combination followed by deescalation improves survival by reducing the risk of delay in appropriate therapy. We know that resolution of episodes with appropriate therapy is similar to core pathogens [5] but that wrong initial therapy is associated with a resolution similar to that of methicillin-resistant Staphylococcus aureus [6].

Pulsed-field electrophoresis analysis performed in an ICU with a high prevalence of PSA identified the genotypes of more than 1,700 isolates [7]. Interestingly, the most frequently isolated clones were responsible for gut or skin colonization, in addition to respiratory colonization, but were only rarely associated with pneumonia. When ventilator-associated pneumonia (VAP) was present, most patients achieved clinical resolution without major consequences. On the other hand, non-related clones suggestive of prior colonization were associated with a very high mortality rate [7]. Most clonally related isolates caused gastric colonization before skin or respiratory tract colonization, suggesting an association with the tap water used in the administration of medication. These findings emphasize that different risk factors may be implicated depending on whether the clone is due to exogenous contamination or or as endogenous colonization from being a carrier. Therefore, conventional identification provided by the microbiology laboratory results is insufficient for assessing the patient and effective management.

Indeed, recent advances have demonstrated the importance of virulence factors in PSA infections. Although several different mechanisms such as quorum sensing and biofilm formation have been reported [8], the TTSS, encoded by PSA, has become one of the most important and widely studied virulence factors. After the microorganism has come into contact with the cell, the needle-like TTSS mechanism allows the bacteria to inject toxins directly into the cytoplasm of the host cell 
[9], evading direct recognition by the host's immune system [10]. Recent studies suggest that failure to eradicate PSA in patients with VAP may be linked to TTSS. Patients infected with Pseudomonas sp. strains which express at least one type of TTSS protein $\left(\mathrm{TTSS}^{+}\right)$at the onset of VAP are more likely to have recovered at day 8 post-VAP, whereas eradication is achieved in patients with undetectable levels of TTSS proteins [11]. The transfer of our knowledge of the virulence factors to the clinical setting is crucial in order to evaluate the potential of virulence factor-directed therapies.

In view of the mortality associated with PSA-VAP $[3,5,12]$ and the frequency of inadequate initial empiric therapy [13-15], these findings underscore the need for a different management paradigm with effective antipseudomonal vaccines for prophylaxis of patients at risk and the need for rapid diagnostic test methods and monoclonal-specific antibodies blocking virulence factors in patients with VAP.

We have also learned that association of virulence factors is a variable that splits $P$. aeruginosa in two phenotypes, with the possibility of adjunctive immunomodulatory therapy for management of virulent strains [16]. A combination of general risk factors and molecular diagnosis techniques may identify suitable candidates for intervention. As in invasive pneumococcal infections [17], further research is required to identify potential associations of comorbidities and serotypes as well as of serotypes and specific complications.

\section{Abbreviations}

PSA: Pseudomonas aeruginosa; TTSS: Type III secretion system; VAP: Ventilatorassociated pneumonia.

\section{Competing interests}

JR has served on advisory boards or speakers bureau (or both) for Kenta Biotech (Zürich-Schlieren, Switzerland), Astellas (Tokyo, Japan), Pfizer Inc. (New York, NY, USA), KaloBios (South San Francisco, CA, USA), Clinigen (Burton-on-Trent, Staffordshire, UK), Roche (Basel, Switzerland), and Bayer (Leverkusen, Germany) and has received research grants from Sanofi Pasteur (Paris, France) and Cubist (Lexington, MA, USA). The other authors declare that they have no competing interests.

\section{Author details \\ 'Critical Care Department, Hospital Vall d'Hebron, Passeig de la Vall d'Hebron, 119-129, 08035 Barcelona, Spain. ${ }^{2}$ CIBERES, Recinto Hospital Joan March, Carretera Soller Km 1207110, Mallorca, Bunyola, Illes Balears, Spain. ${ }^{3}$ Vall d'Hebron Institute of Research, Passeig de la Vall d'Hebron, 119-129, 08035 Barcelona, Spain. ${ }^{4}$ Universitat Autònoma de Barcelona, Plaça Cívica, Campus de la UAB,Sardañola del Vallés, 08193 Barcelona, Spain.}

Published: 29 Apr 2014
International study of the prevalence and outcomes of infections in intensive care units. JAMA 2009, 302:2323-2329.

3. Tumbarello M, Sali M, Trecarichi EM, Leone F, Rossi M, Fiori B, De Pascale G, D'Inzeo T, Sanguinetti M, Fadda G, Cauda R, Spanu T: Clinical outcomes of Pseudomonas aeruginosa pneumonia in intensive care unit patients. Intensive Care Med 2013, 39:682-692.

4. Garnacho-Montero J, Sa-Borges M, Sole-Violan J, Barcenilla F, EscorescaOrtega A, Ochoa M, Cayuela A, Rello J: Optimal management therapy for Pseudomonas aeruginosa ventilator-associated pneumonia: an observational, multicenter study comparing monotherapy with combination antibiotic therapy. Crit Care Med 2007, 35:1888-1895.

5. Rello J, Ricart M, Ausina V, Net A, Prats G: Pneumonia due to Haemophilus influenzae among mechanically ventilated patients. Incidence, outcome, and risk factors. Chest 1992, 102:1562-1565.

6. Vidaur L, Planas K, Sierra R, Dimopoulos G, Ramirez A, Lisboa T, Rello J: Ventilator-associated pneumonia: impact of organisms on outcomes and medical resources utilization. Chest 2008, 133:625-633.

7. Vallés J, Mariscal D, Cortés P, Coll P, Villagrá A, Díaz E, Artigas A, Rello J: Patterns of colonization by Pseudomonas aeruginosa in intubated patients: a 3-year prospective study of 1,607 isolates using pulsed-field gel electrophoresis with implications for prevention of ventilatorassociated pneumonia. Intensive Care Med 2004, 30:1768-1775.

8. Hueck CJ: Type III protein secretion systems in bacterial pathogens of animals and plants. Microbiol Mol Biol Rev 1998, 62:379-433.

9. Veesenmeyer JL, Hauser AR, Lisboa T, Rello J: Pseudomonas aeruginosa virulence and therapy: evolving translational strategies. Crit Care Med 2009, 37:1777-1786.

10. Shime N, Sawa T, Fujimoto J, Faure K, Allmond LR, Karaca T, Swanson BL, Spack EG, Wiener-Kronish JP: Therapeutic administration of anti-PcrV F $\left(a b^{\prime}\right)(2)$ in sepsis associated with Pseudomonas aeruginosa. J Immunol 2001, 167:5880-5886.

11. El Solh AA, Akinnusi ME, Wiener-Kronish JP, Lynch SV, Pineda LA, Szarpa K: Persistent infection with Pseudomonas aeruginosa in ventilatorassociated pneumonia. Am J Respir Crit Care Med 2008, 178:513-519.

12. Crandon JL, Ariano RE, Zelenitsky SA, Nicasio AM, Kuti JL, Nicolau DP: Optimization of meropenem dosage in the critically ill population based on renal function. Intensive Care Med 2011, 37:632-638.

13. Venier AG, Gruson D, Lavigne T, Jarno P, L'Hériteau F, Coignard B, Savey A, Rogues AM, REA-RAISIN group: Identifying new risk factors for Pseudomonas aeruginosa pneumonia in intensive care units: experience of the French national surveillance, REA-RAISIN. J Hosp Infect 2011, 79:44-48.

14. Hurley JC: Paradoxical ventilator-associated pneumonia incidences among selective digestive decontamination studies versus other studies of mechanically ventilated patients: benchmarking the evidence base. Crit Care 2011, 15:R7.

15. Rello J, Allegri C, Rodriguez A, Vidaur L, Sirgo G, Gomez F, Agbaht K, Pobo A, Diaz E: Risk factors for ventilator-associated pneumonia by Pseudomonas aeruginosa in presence of recent antibiotic exposure. Anesthesiology 2006, 105:709-714.

16. Van Delden C, Kohler T, Brunner-Ferber F, Francois B, Carlet J, Pechere JC: Azithromycin to prevent Pseudomonas aeruginosa ventilator- associated pneumonia by inhibition of quorum sensing: a randomized controlled trial. Intensive Care Med 2012, 38:1118-1125.

17. Luján M, Burgos J, Gallego M, Falcó V, Bermudo G, Planes A, Fontanals D, Peghin M, Monsó E, Rello J: Effects of immunocompromise and comorbidities on pneumococcal serotypes causing invasive respiratory infection in adults: implications for vaccine strategies. Clin Infect Dis 2013, 57:1722-1730

$10.1186 / \mathrm{cc} 13849$

Cite this article as: Rello et al:: Management of Pseudomonas aeruginosa pneumonia: one size does not fit all. Critical Care 2014, 18:136

\section{References}

1. Lu Q, Eggimann P, Luyt CE, Wolf M, Tamm M, François B, Merceir E, Garbino J, Laterre PF, Koch H, Gafner V, Rudolf MP, Mus E, Perez A, Lazar H, Chastre $\mathrm{J}$, Rouby JJ: Pseudomonas aeruginosa serotypes in nosocomial pneumonia: prevalence and clinical outcomes. Crit Care 2014, 18:R17.

2. Vincent JL, Rello J, Marshall J, Silva C, Anzueto A, Martin CD, Moreno R, Lipman J, Gomersall C, Sakr Y, Reinhart K, EPIC II Group of Investigators: 